\title{
Do patients want to be informed? A study of consent for cardiac catheterisation
}

\author{
ALAN G FRASER \\ From the Department of Cardiology, University Hospital of Wales, Cardiff
}

SUMMARY One hundred and four patients were asked to recall what they had been told before they gave consent for cardiac catheterisation to be performed. Of these, $14 \%$ had received no explanation, $24 \%$ had not been warned to expect specific symptoms or side effects, $40 \%$ had been told that complications were possible, and $26 \%$ had been warned that there was a risk of death. Most patients did not know about these risks, and two thirds would not have wanted to be told about them. Doctors should neither insist on gaining fully informed consent from anxious patients nor deny detailed information to inquiring ones.

In the United Kingdom doctors need not disclose all the risks of a procedure to each patient, ${ }^{1}$ so they sometimes withhold information in the belief that they are preventing unnecessary worry. Since patients' attitudes to informed consent have rarely been studied the adequacy of consent obtained before cardiac catheterisation was assessed by comparing what patients understood about the procedure and its risks with their estimates of how much they wanted to be told and with current legal guidelines.

\section{Patients and methods}

One hundred and four randomly selected patients were interviewed by one of five medical students less than two days after elective cardiac catheterisation using a standard questionnaire. All had undergone routine catheterisation after premedication with 10 mg diazepam orally. Consent was obtained in the normal manner by doctors, usually house physicians, who did not know about the study or its purpose; this was confirmed by direct inquiry when the study was completed. Subjects were asked not to disclose any questions to other patients, and if asked about the project the students explained only that they were studying "what patients think about catheter tests."

Sixty men and 44 women aged 18-74 years (mean 49 , SD 12) years were studied; their social class distribution was similar to the 1971 UK census. Of

Requests for reprints to Dr A G Fraser, Department of Cardiology, University Hospital of Wales, Heath Park, Cardiff CF4 4XW.

Accepted for publication 26 June 1984
Table 1 Recall of cardiac catheterisation. Figures are numbers and percentages of patients

\begin{tabular}{lll}
\hline \multicolumn{1}{c}{ Procedure } & No & $\%$ \\
\hline \multicolumn{1}{c}{${ }^{\star}$} & 21 & 31 \\
Right heart catheterisation (68) & 66 & 65 \\
Left heart catheterisation (102) & 96 & 94 \\
Angiography (102) & 15 & 14 \\
Manometry (104) & \\
& & \\
Effects of contrast media & Symptomst & 73 \\
Local anaesthetic injection & 37 \\
Pain at site of catheter insertion & 36 \\
Palpitation & 16 \\
Chest pain & 13 \\
Backache & 3 \\
Dyspnoea & & 3 \\
\hline
\end{tabular}

* Figure in parenthesis is the number of patients who had each procedure.

tReported as percentage of all patients at risk of each symptom.

these, $48 \%$ had valvar heart disease and $38 \%$ coronary artery disease, including some with both; others had congenital heart disease (7\%), cardiomyopathy (7\%), or no abnormal findings $(6 \%)$.

\section{Results}

Most patients understood and recalled angiography, but few could describe right heart catheterisation or the measurement of intracardiac pressures (Table 1); $93 \%$ remembered some unpleasant symptoms; $14 \%$ had been very apprehensive.

Some patients received no explanation from doctors (Table 2), but most of these $(9 / 15,60 \%)$ had not wanted one. Other patients had wanted more infor- 
Table 2 Sources and adequacy of information about cardiac catheterisation. Figures are percentages of all patients $(n=104)$

\begin{tabular}{lc}
\hline \multicolumn{1}{c}{ Medical sources of information } & $(86 \%)$ \\
Consultant & 9 \\
Senior registrar or registrar & 27 \\
Senior house officer & 8 \\
House officer & 40 \\
Other doctor not identified & 13 \\
No explanation from doctors & 14 \\
No information from any source & 4 \\
\multicolumn{1}{c}{$\quad$ Information from other patients } & $(64 \%)$ \\
Factual statements & 18 \\
Reassurance & 43 \\
Comments which caused anxiety & 10 \\
& \\
Explanation not understood & 3 \\
More information wanted & 20 \\
Written information would be helpful & 25 \\
\hline
\end{tabular}

${ }^{\star}$ More than one answer possible. The total percentage who obtained information from these sources is given in parenthesis.

Table 3 Recall of previous warnings. Figures are percentages of all patients $(n=104)$

\begin{tabular}{lr}
\hline Symptoms during catheterisation: & \\
Effects of contrast media & 75 \\
Palpitation & 11 \\
Bleeding or bruising & 6 \\
General discomfort & 4 \\
Possible allergic reaction & 1 \\
Other & 8 \\
No specific warnings recalled & 24 \\
Complications mentioned in general & 40 \\
Risk to life: & 26 \\
Explained to patient & 15 \\
Assumed by patient & 59 \\
Not understood & 17 \\
Known by relatives & \\
\hline
\end{tabular}

mation but half $(10 / 21,48 \%)$ had not had the opportunity to ask questions. A few (4\%) thought the procedure had been a form of treatment rather than an investigation. Seventy six per cent had been warned that they might experience particular symptoms during cardiac catheterisation (Table 3). Some patients had been told that it carried a risk to their life; others had assumed this because of previous knowledge or deduced it because they were asked to sign a consent form. Most of the patients who did not appreciate this risk $(37 / 61,62 \%)$ would not have wanted to be told about it. Forty two per cent of the patients who knew the risks had told their relatives; $18 \%$ of those who had not been told would have wanted their relatives to know.

Eighty six per cent of the patients would have given consent whatever the risk involved. Others gave estimates of the risk of death which they would have accepted as being between 1 in 100 and 1 in 4000 (mean 1 in $933, n=7$ ). When told that the risk of death from cardiac catheterisation was about 1 in $1000,99 \%$ said that if they had been told this they would still have given consent.

\section{Discussion}

Many patients were poorly informed about cardiac catheterisation and its risks. Premedication with diazepam may have contributed to poor recall of the procedure but not to poor recall of the consent interview, because it does not cause retrograde amnesia. ${ }^{2}$ Patients may have forgotten risks which had been mentioned to them, as other authors report, ${ }^{3}$ but this could not be tested because observation would have influenced the doctors while they obtained consent. Nevertheless patients usually remember the most important things that doctors tell them. ${ }^{4}$

When patients receive no explanation, as reported by $14 \%$ in this study, consent may be invalid even when a form has been signed. ${ }^{5}$ When a doctor has explained a procedure but failed to disclose its risks he may be negligent when a complication occurs ${ }^{6}$ but only if in similar circumstances a reasonable doctor would have informed his patient and if the patient would then not have suffered injury because he would not have given consent. The duty to disclose risks is greater when a procedure is not essential or is associated with particular risks ${ }^{1}$; nevertheless, legal precedent suggests that the risks of elective cardiac catheterisation fall between the extremes where disclosure is considered unnecessary or mandatory. ${ }^{5}$ The Court of Appeal recently reaffirmed that what to disclose is a matter of medical judgment ${ }^{7}$ so most patients in this study were probably adequately informed in a legal sense.

Doctors who impose informed consent on patients, such as those in this study who did not want to know the risks of catheterisation, may be practising an ethically unjustifiable form of medical paternalism. ${ }^{8}$ Nevertheless, a substantial minority did want more information, and those patients who ask questions must be given more detailed answers. ${ }^{9}$ More explanation could have helped those who were apprehensive or exposed to misleading comments from other patients. There was no evidence that disclosure of the main risks of catheterisation would have prevented patients from giving consent.

Consent procedures should be based on each patient's wishes and requirements rather than on rigid rules. Doctors should take time to talk to their patients in a sympathetic way and encourage them to ask questions in order to try to determine how much they want to know. Consent should be obtained without stress, on a different day, and in a different environment from those of the procedure. If the doctor who is to perform cardiac catheterisation delegates his responsibility to obtain consent he should ensure that his junior colleagues are familiar with the procedure and its risks. Training and supervision in interviewing skills and the obtaining of informed consent should be 
available to medical students and newly qualified graduates.

I thank Professor A H Henderson, Dr L G Davies, Dr M R Stephens, and Dr D J Sheridan for permission to study their patients.

\section{References}

1 Samuels A. What the doctor must tell the patient. Med Sci Law 1982; 22: 41-6.

2 Clarke PRF, Eccersley PS, Frisby JP, Thornton JA. The amnesic effect of diazepam (valium). Br $\mathcal{F}$ Anaesth 1970; 42: $690-7$.

3 Cassileth BR, Zupkis RV, Sutton-Smith K, March V.
Informed consent - why are its goals imperfectly realized? N Engl f Med 1980; 302: 896-900.

4 Health Education Studies Unit. Final report on the patient project. London: Health Education Council, 1982.

5 Chatterton v Gerson. Weekly Law Report 1980; 3: 100315.

6 Lord Hailsham, ed. Halsbury's laws of England. 4th ed. Vol 30. London: Butterworths, 1980: 34.

7 Brahams D. The surgeon's duty to warn of risks: transatlantic approach rejected by Court of Appeal. Lancet 1984 ; i: $578-9$.

8 Gert B, Culver CM. Paternalistic behaviour. In: Cohen $M$, Nagel T, Scanlon T, eds. Medicine and moral philosophy. Princeton: Princeton University Press, 1982: 20113.

9 Robertson G. Informed consent to medical treatment. Law Quarterly Review 1981; 97: 102-26. 